\title{
Anti-inflammatory activity of extracts of Bushen-Qiangdu-Zhilv decoction, a Chinese medicinal formula, in M1-polarized RAW264.7
}

\author{
Run-Yue Huang ${ }^{1}$, Jie-Hua Lin ${ }^{1}$, Xiao-Hong He ${ }^{1}$, Xiong Li ${ }^{2}$, Chuan-Li Lư ${ }^{2}$, Ying-Yan Zhou ${ }^{1}$, Jun Cai ${ }^{3}$ and Yi-Ting He ${ }^{1 *}$
}

\begin{abstract}
Background: Bushen-Qiangdu-Zhilv Decoction (BQZ) is one of famous traditional Chinese medical formula for treating ankylosing spondylitis (AS). However, the mechanisms underlying effects of $\mathrm{BQZ}$ remains unknown. Pro-inflammatory cytokines, tumor necrosis factor (TNF)-a and interleukin (IL)-1, play an important role in AS. We therefore evaluated if $\mathrm{BQZ}$ could affect the expression of these cytokines.

Methods: Crude extracts were prepared and fractioned with petroleum ether (PE), ethyl acetate (EA), n-butanol (BU) and finally water (ACE). The stability of the extracts was confirmed by high-pressure liquid chromatography (HPLC) analysis. M1-polarized RAW264.7 was induced and subsequently treated with BQZ extracts. Quantitative real-time PCR experiments were performed to measure mRNA expression of TNF- $a$ and IL-1.

Results: It was found that TNF-a could be significantly suppressed by ACE extracts, whereas IL-1 was dramatically inhibited by BU extracts, which was further confirmed by dose-dependent experiments. Importantly, MTS assays showed that both ACE and BU extracts had a low cytotoxicity.

Conclusion: Altogether, our study indicates that BQZ decoction exerts anti-AS effects via its anti-inflammatory activity and may have a low side-effect. Further analysis of the extracts of BQZ decoction could lead to a discovery of some novel drugs adding to therapeutic strategy for AS patients.
\end{abstract}

\section{Background}

Ankylosing spondylitis (AS) is a systemic inflammatory disease characterized by chronic inflammation of the axial skeleton, the peripheral joints, enthuses as well as the attachments of ligaments [1]. The prevalence of AS is $0.20 \%-0.54 \%$ among Han-Chinese population, which is similar to the prevalence in Europe and America [2]. Regarding therapeutic approaches aimed to treat AS, nonsteroidal anti-inflammatory drugs (NSAIDs) have been considered as the cornerstone of treatment for AS, but still, they are not effective in some cases. Disease-modifying antirheumatic drugs (DMARDs), such as sulfasalazine and methotrexate, are only recommended for treating AS with peripheral arthritis or extra-articular features [3,4]. However, in cases of exclusive spinal involvement that do not

\footnotetext{
* Correspondence: yitinghe@126.com

'Department of Rheumatology, The Second Affiliated Hospital, Guangzhou University of Chinese Medicine (Guangdong Provincial Hospital of Chinese Medicine), Guangzhou 510006, China

Full list of author information is available at the end of the article
}

respond to NSAIDs, the merely option is to adopt antitumor necrosis factor (TNF) agents [4]. Because anti-TNF therapy suppresses the immune system [5], serious infections are the most frequently reported adverse events of interest across indications for the anti-TNF drugs [6]. In addition, given the role of TNF in mediating tumor growth [5], the risk of malignancy with anti-TNF therapy has been a concern [7], and there is substantial evidence that the chronic inflammation inherent in the conditions treated with anti-TNF therapy is itself associated with an increased potential for malignancy $[6,8]$.

Fortunately, traditional Chinese medicine provides an alternative, or better, choice for AS patients. For example, traditional Chinese medical treatment, while effective in treating rheumatoid arthritis, appears to be less effective than Western medical treatment in controlling symptoms, but traditional Chinese medical treatment is associated with fewer side effects [9]. Bushen-Qiangdu-Zhilv Decoction (BQZ) was established by Prof. Shu-De Jiao who is a well-known traditional Chinese medicine master in 
Rheumatology. Modified BQZ decoction has been demonstrated to be more effective than sulfasalazine, a typical DMARD for treating AS, in relieving clinical symptoms and signs as well as inflammatory activity indicators of AS patients [10]. However, the mechanisms underlying BQZ decoction effects remains unclear. Herein, in this study, the crude extracts of BQZ decoction was prepared and fractioned, and effects of crude extracts of BQZ decoction on pro-inflammatory cytokines, TNF- $\alpha$ and interleukin (IL)-1, were determined.

\section{Methods}

\section{Cell lines and cell culture}

RAW 264.7 macrophage-like cell line was ordered from American Type Culture Collection (Rockville, MD, USA) and cultured in Dulbecco's Modified Eagle's Medium supplemented with $10 \%$ fetal bovine serum (FBS). To induce M1-polarized RAW264.7, $100 \mathrm{ng} / \mathrm{ml}$ interferon (IFN)- $\gamma$ was added to cultures for $24 \mathrm{~h}$ prior to stimulation with crude extracts of BQZ decoction. Cell lines were propagated at $37^{\circ} \mathrm{C}$ in an atmosphere of $5 \% \mathrm{CO}_{2}$.

\section{Extraction and separation}

Bushen-Qiangdu-Zhilv (BQZ) formula is composed of 22 species of herbal plants. All components, purchased from KANGMEI pharmaceutical Co., LTD (Guangzhou, China), were identified by our authors (Prof. Yi-Ting He and Dr. Xiao-Hong He). The formula of BQZ is described in Table 1.

Total $352 \mathrm{~g}$ of BQZ formula was boiled with $1.5 \mathrm{~L}$ ultrapure water in a Chinese medicine decocting pot (Guangzhou WEN XIN electronics co., LTD., China) for $2 \mathrm{~h}$, yielding final $400 \mathrm{ml}$ of solution. The obtained solution was filtered and subsequently dried using a centrifugal evaporator (Genevac Ltd., UK) for $48 \mathrm{~h}$, following evaporated in a rotavapor (IKA laboratory, Germany) at $25^{\circ} \mathrm{C}$. Finally, $6.4 \mathrm{~g}$ crude extract of BQZ decoction was obtained.

$6.4 \mathrm{~g}$ of the crude extract were suspended in $400 \mathrm{ml}$ ultrapure water and the solution was extracted three times with $500 \mathrm{ml}$ of solvents of different polarity starting with petroleum ether (PE), ethyl acetate (EA), n-butanol (BU) and finally water (ACE). The obtained fractions were evaporated to dryness yielding $0.09 \mathrm{~g}$ petroleum ether, $0.72 \mathrm{~g}$ ethyl acetate, $0.549 \mathrm{~g}$ n-butanol and $4.50 \mathrm{~g}$ water fraction. High-pressure liquid chromatography (HPLC) analysis was performed as previously described [11]. To observe which fractioned extracts is responsible for the BQZ effects, $50 \mu \mathrm{g} / \mathrm{ml}$ of these crude extracts were used to stimulate M1-polarized RAW264.7 for $24 \mathrm{~h}$.

\section{Flow cytometric analysis}

The M1 polarized RAW264.7 was washed with PBS, and cells were subsequently stained with FITC-conjugated
Table 1 The components of BQZ formula

\begin{tabular}{ll}
\hline Components of formula & Quantity \\
\hline Rhizoma Drynariae & $18 \mathrm{~g}$ \\
Fructus psoraleae & $12 \mathrm{~g}$ \\
Radix Rehmanniae Praeparata & $15 \mathrm{~g}$ \\
Herba epimedii & $12 \mathrm{~g}$ \\
Notopterygium root & $12 \mathrm{~g}$ \\
Rhizome cibotii & $30 \mathrm{~g}$ \\
Radix angelicae pubescentis & $10 \mathrm{~g}$ \\
Dipsacus root & $18 \mathrm{~g}$ \\
Eucommia ulmoides & $20 \mathrm{~g}$ \\
Medicinal cyathula root & $12 \mathrm{~g}$ \\
Herba lycopi & $15 \mathrm{~g}$ \\
Cassia twig & $15 \mathrm{~g}$ \\
Rhizome anemarrhenae & $15 \mathrm{~g}$ \\
Radix aconiti carmichaeli (Cooked and sliced) & $12 \mathrm{~g}$ \\
honey-fried herba ephedrae & $6 \mathrm{~g}$ \\
Rhizome zingiberis & $6 \mathrm{~g}$ \\
Rhizoma atractylodis macrocephalae & $10 \mathrm{~g}$ \\
Radix clematidis & $15 \mathrm{~g}$ \\
Radix Saposhnikoviae & $12 \mathrm{~g}$ \\
Raw semen coicis & $30 \mathrm{~g}$ \\
Root of common peony & $12 \mathrm{~g}$ \\
Radix paeoniae alba & $12 \mathrm{~g}$ \\
\hline
\end{tabular}

antibody, directed against cell surface marker CD86 [12], or with corresponding isotype controls for $20 \mathrm{~min}$ at $4^{\circ} \mathrm{C}$. Cells were analyzed using FACSCalibur (Becton Dickinson, Erembodegem, Belgium). Data were analyzed using fluorescence-activated cell sorting (FACS) analysis and shown as mean fluorescent intensity (MFI).

\section{Reverse transcriptase and quantitative real-time PCR}

Total RNA was extracted using Trizol reagent (Invitrogen, Grand Island, NY), and cDNA was subsequently synthesized from $2 \mu \mathrm{g}$ of total RNA using a high capacity cDNA reverse transcription kit (Promega, Madison, WI), according to the manufacturer's instruction. Quantitative real-time PCR was performed using gene-specific primers and SYBR Green qPCR SuperMix (Bio-Rad Laboratories, Inc. Berkeley, $\mathrm{CA}$ ). The following primer sequences were used: GAPDH, (forward) 5'-GTTTTCAGGGATGAAGC GGC-3' and (reverse) 5' -TTTGTCAAGCTCATTTCCTG GTATG-3'; TNF-a, (forward) 5'-GTGTCCCAACATTC ATATTGTCAGT-3' and (reverse) 5' ${ }^{\prime}$-TGGGAAGAGAAA CCAGGGAGA-3'; IL-1, (forward) 5' -TGGGATAGGGC CTCTCTTGC-3' and (reverse) 5' -CCATGGAATCCGTG TCTTCCT-3'; arg1, (forward) 5' -TACAAGACAGGGCT CCTTTCAG-3' and (reverse) 5' ${ }^{\prime}$-TGAGTTCCGAAGCA 
AGCCAA-3'; iNOS, (forward) 5'-TGAGTTCCGAAGC AAGCCAA-3' and (reverse) 5' -AGACCTCAACAGAGCC CTCA-3'.

Real-time PCR was performed using the CFX96 Touch Deep Well ${ }^{\text {m }}$ Real-Time PCR Detection System (Bio-Rad) with the following steps: $50^{\circ} \mathrm{C} 2 \mathrm{~min}, 95^{\circ} \mathrm{C} 10 \mathrm{~min}, 40$ cycles at $95^{\circ} \mathrm{C} 15 \mathrm{~s}$ and $60^{\circ} \mathrm{C} 60 \mathrm{~s}$. The expression of target genes in the treatment and control groups was normalized using the house-keeping gene GAPDH and the fold change in the expression of each target gene was calculated by the 2- $\Delta \Delta \mathrm{CT}$ method.

\section{Cytotoxicity assay}

Cytotoxicity of ACE and BU extracts was detected by MTS, i.e., CellTiter $96^{\circ}$ AQueous One Solution Cell Proliferation Assay, according to the manufacturer's instruction (Promega). Briefly, cells were seeded at the same density into 96-well plates and incubated overnight for attaching. After proper treatment, the control and treated cells were incubated for the indicated times. Following adding $20 \mu \mathrm{l}$ of MTS [3-(4,5-dimethylthiazol-2-yl)-5-(3-carboxymethoxyphenyl)-2-(4-sulfophenyl)-2H-tetrazolium, inner salt] in each micro well, and plate was read using a microplate reader at wavelength of $492 \mathrm{~nm}$ (Bio-Rad, Philadelphia, PA, USA).

\section{Statistical analyses}

Data are shown as means \pm SD from experiments repeated at least twice. For the comparisons between two groups, Student's $t$ test was utilized. One-way ANOVA followed by Dunnett's test was employed for comparisons among more than two groups. Statistical analyses were conducted by SPSS 11.6 statistical software (SPSS, Chicago, IL). A two-tailed $\mathrm{P}$ value of $<0.05$ was considered to indicate statistical significance.

\section{Results}

\section{In vitro $\mathrm{M} 1$ macrophage polarization}

M1 macrophage phenotype was induced on RAW264.7 by stimulating with $100 \mathrm{ng} / \mathrm{ml} \mathrm{IFN}-\gamma$ for $24 \mathrm{~h}$ (Figure 1A). Flow cytometric analysis were conducted to examine CD86 expression in cell surface, since CD86 is well-known to be a signature marker of M1 macrophage. As shown in Figure 1B, CD86 was expressed in 96.5\% RAW264.7 exposed to IFN- $\gamma$, confirming M1 polarization of RAW264.7. Real-time PCR further confirmed the data obtained by flow cytometric analysis. The overall polarization of RAW264.7 shifted to M1, as inducible nitric oxide synthase (iNOS) expression increased and arginase (Arg)-1 expression decreased (Figure 1C) [12].

Effects of crude extracts on TNF- $a$ and IL-1 mRNA expression The crude extracts, including extracts fractioned by $\mathrm{PE}, \mathrm{EA}, \mathrm{BU}$ and finally $\mathrm{ACE}$, were used to treat the
M1-polarized macrophages. PE extracts was not used, since cells were totally killed when treating with PE extracts. M1-polarized RAW264.7 was stimulated with $50 \mu \mathrm{g} / \mathrm{ml}$ of these crude extracts for $24 \mathrm{~h}$ respectively. M1-polarized RAW264.7 without treatment was used as the controls. Total RNA was extracted from cell lysates and subjected to quantitative real-time PCR experiments. As shown in Figure 2A, ACE extracts significantly suppressed mRNA expression of TNF- $\alpha$ by about 4.0-fold of control with $\mathrm{p}<0.01$. In addition, EA extracts reduced TNF- $\alpha$ mRNA expression by about 2.0 -fold of control $(p<0.05)$. However, both ACE and EA extracts did not have significant effects on IL-1 mRNA expression (Figure 2B). Interestingly, BU extracts had an opposite effects. The level of IL-1 mRNA, but not TNF- $\alpha$ mRNA was dramatically decreased by BU extracts by more than 7.0-fold of control (Figure 2B, p $<0.01$ ). Herein, it appears that EA extracts are responsible for targeting TNF- $\alpha$, while BU extracts are accountable for suppressing IL-1 in BQZ decoction. Further experiments were conducted to verify the effects of EA and BU extracts on pro-inflammatory cytokines.

The preparation of crude extracts and the subsequently HPLC experiments were performed more than three times. As illustrated in Figure 3, HPLC chromatograms of total, $\mathrm{ACE}$ and $\mathrm{BU}$ extracts of $\mathrm{BQZ}$ decoction prepared from three independent experiments were quite similar, suggesting the stability of the extracts and the preparation technology.

\section{ACE extracts suppressed TNF- $\alpha$ expression with a low cytotoxicity}

To confirm the suppressing effects of ACE extracts on mRNA expression of TNF- $\alpha$ in M1-polarized phenotype, RAW264.7 was treated with graded levels of ACE extracts following $24 \mathrm{~h}$ stimulation with $100 \mathrm{ng} / \mathrm{ml}$ IFN- $\gamma$. As shown in Figure 4A, mRNA level of TNF- $\alpha$ was suppressed by ACE extracts in a dose-dependent manner. The expression of TNF- $\alpha$ mRNA was almost completely inhibited when cells exposed to ACE extracts at the concentrations from $100 \mu \mathrm{g} / \mathrm{ml}$ to $500 \mu \mathrm{g} / \mathrm{ml}(\mathrm{p}<0.001$ respectively).

To determine if the decreased levels of TNF- $\alpha$ mRNA were due to cell death, cells survival was examined by MTS assays. MTS assay is an update method from MTT assay, which is a typical and widely used tool for measurement of cell survival. After stimulation with $100 \mathrm{ng} / \mathrm{ml}$ IFN- $\gamma$, RAW264.7 was treated graded levels of ACE extracts for $24 \mathrm{~h}$ and MTS experiments were subsequently conducted. Surprisingly, ACE extracts did not affect cell survival significantly, even at the concentration of $500 \mu \mathrm{g} / \mathrm{ml}$ (Figure 4B). Our findings suggest that ACE extracts can suppress expression of TNF- $\alpha$ mRNA in M1-polarized RAW264.7 with a low cytotoxicity. 


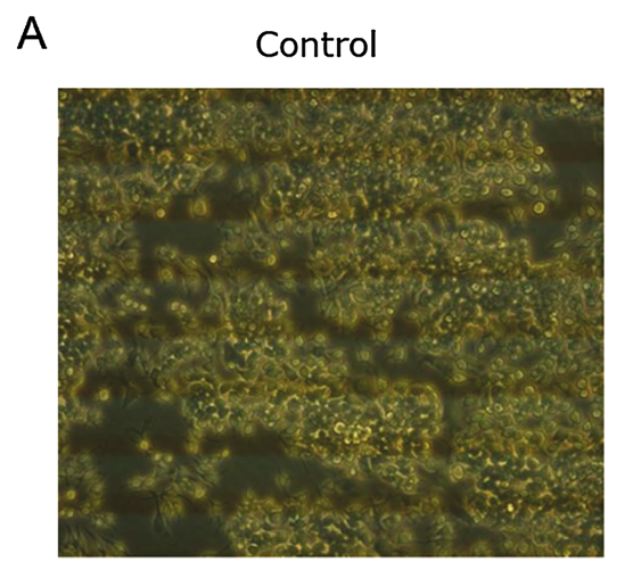

B

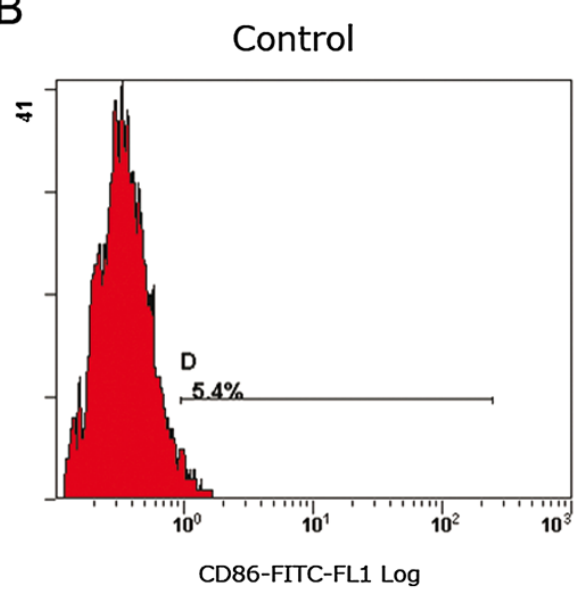

C

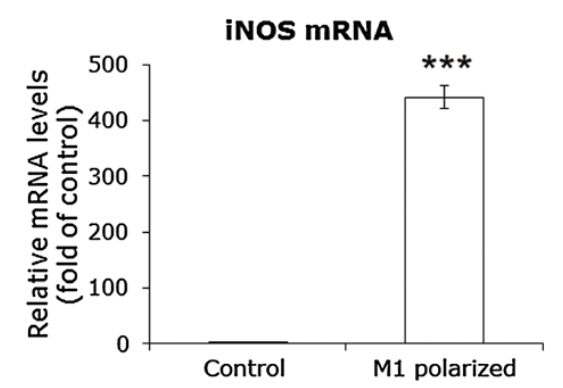

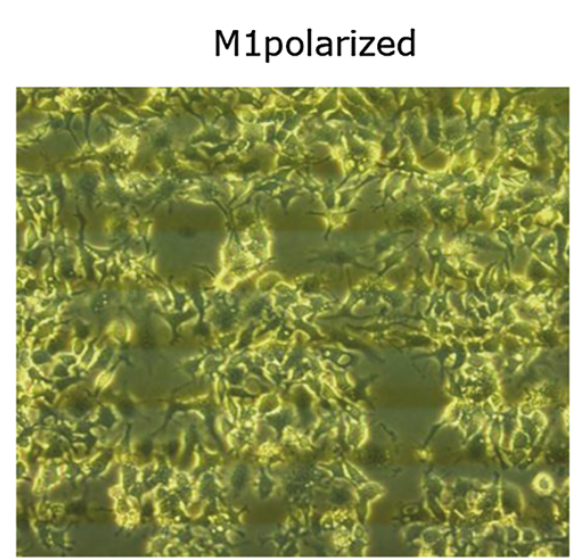

M1polarized

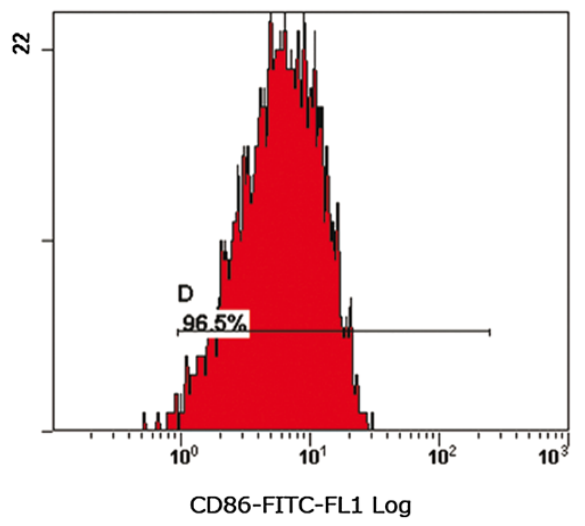

Arg-1 mRNA

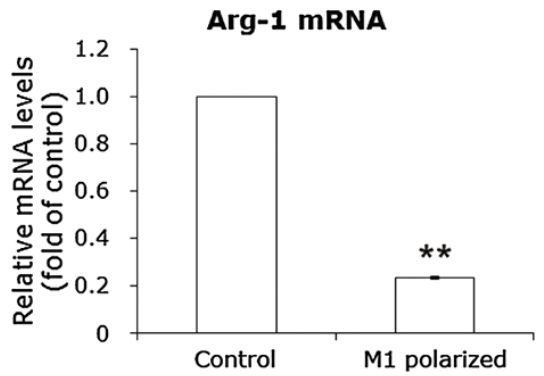

Figure 1 Induction of M1-polarized RAW264.7. RAW264.7 was polarized toward the M1 phenotype by stimulating with $100 \mathrm{ng} / \mathrm{ml}$ IFN- $\gamma$ for 24 h. A, microscope shots pictures of RAW264.7. The right panel is the M1 phenotype. B, flow cytometry detection of CD86, a signature marker of M1 cells. $\mathbf{C}$, the relative mRNA levels of iNOS and Arg-1 were determined by real-time PCR. The mRNA levels of these two molecules in RAW264.7 without treatment were used as the controls. Data are presented as mean \pm SD of three independent experiments done in triplicate. ${ }^{* *} p<0.05$ and ${ }^{* *} \mathrm{P}<0.001$ versus control.

\section{BU extracts suppressed IL-1 expression with a low cytotoxicity}

RAW264.7 was treated with increasing concentrations of BU extracts following $24 \mathrm{~h}$ stimulation of $100 \mathrm{ng} / \mathrm{ml}$ IFN- $\gamma$. Figure $5 \mathrm{~A}$ showed that BU extracts could dosedependently inhibit IL-1 mRNA expression. $50 \mu \mathrm{g} / \mathrm{ml} \mathrm{BU}$ extracts significantly suppressed IL-1 mRNA expression $(\mathrm{p}<0.05)$, which is in line with the data shown in Figure 2B. In addition, BU extracts totally abrogated the increased expression of IL-1 mRNA in M1-polarized RAW64.7 to the level under control $(\mathrm{p}<0.001)$. MTS assays demonstrated that increasing concentrations of $\mathrm{BU}$ extracts could not kill M1-polarized RAW2647, albeit there was an inhibitory trend (Figure $5 \mathrm{~B}$ ). Together, these 

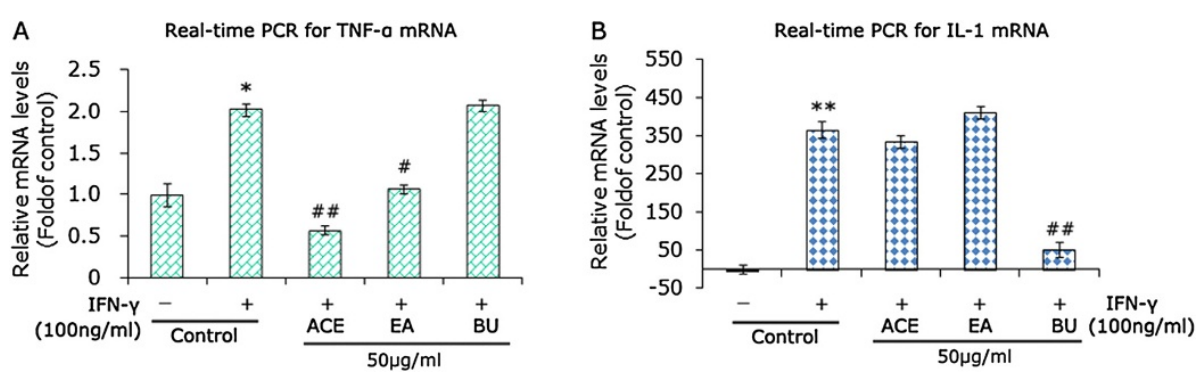

Figure 2 Effects of fractioned extracts on TNF- $a$ and IL-1 mRNA expression. Quantitative real-time PCR evaluation for the effects of crude extracts of BQZ decoction on mRNA expression of TNF-a (A) and IL-1 (B). M1-polarized RAW264.7 was stimulated with the different crude extracts $(50 \mathrm{\mu g} / \mathrm{ml}$ respectively) for $24 \mathrm{~h}$. The M1-polarized RAW2647 without extracts stimulation were used as control and RAW264.7 without treatment were employed as the additional controls. Total RNA was extracted and subjected to real-time PCR experiments. Data are expressed as mean \pm SD of three independent experiments done in triplicate. ${ }^{*} p<0.01$ and ${ }^{* *} \mathrm{P}<0.01$ versus the additional controls, while \#p $<0.05$ and \#\#p $<0.01$ versus control.

data strongly suggest that $\mathrm{BU}$ extracts is able to suppress IL-1 expression with a low cytotoxicity.

\section{Discussion}

Macrophage activation plays an important role in the pathology of AS $[7,10,13]$. Macrophages are a population of cells derived from CD34 positive bone marrow progenitors, from which blood pro-monocytes are differentiated and developed into monocytes which extravasate into tissues where they become "resident" tissue macrophages
[14]. Macrophages may be recruited and subsequently activated as consequence of any local disturbance of tissue homeostasis, such as infections, immune response and malignancy $[7,15]$. Activated macrophages, also known as polarized macrophages, present different phenotypes, M1 (classical activation) and M2 (alternative activation) in general, in relation to the nature of the recruiting stimulus and the location $[7,16]$. These two polarized phenotypes are considered to exhibit opposing activities, being either polarized towards pro-inflammatory or anti-inflammatory
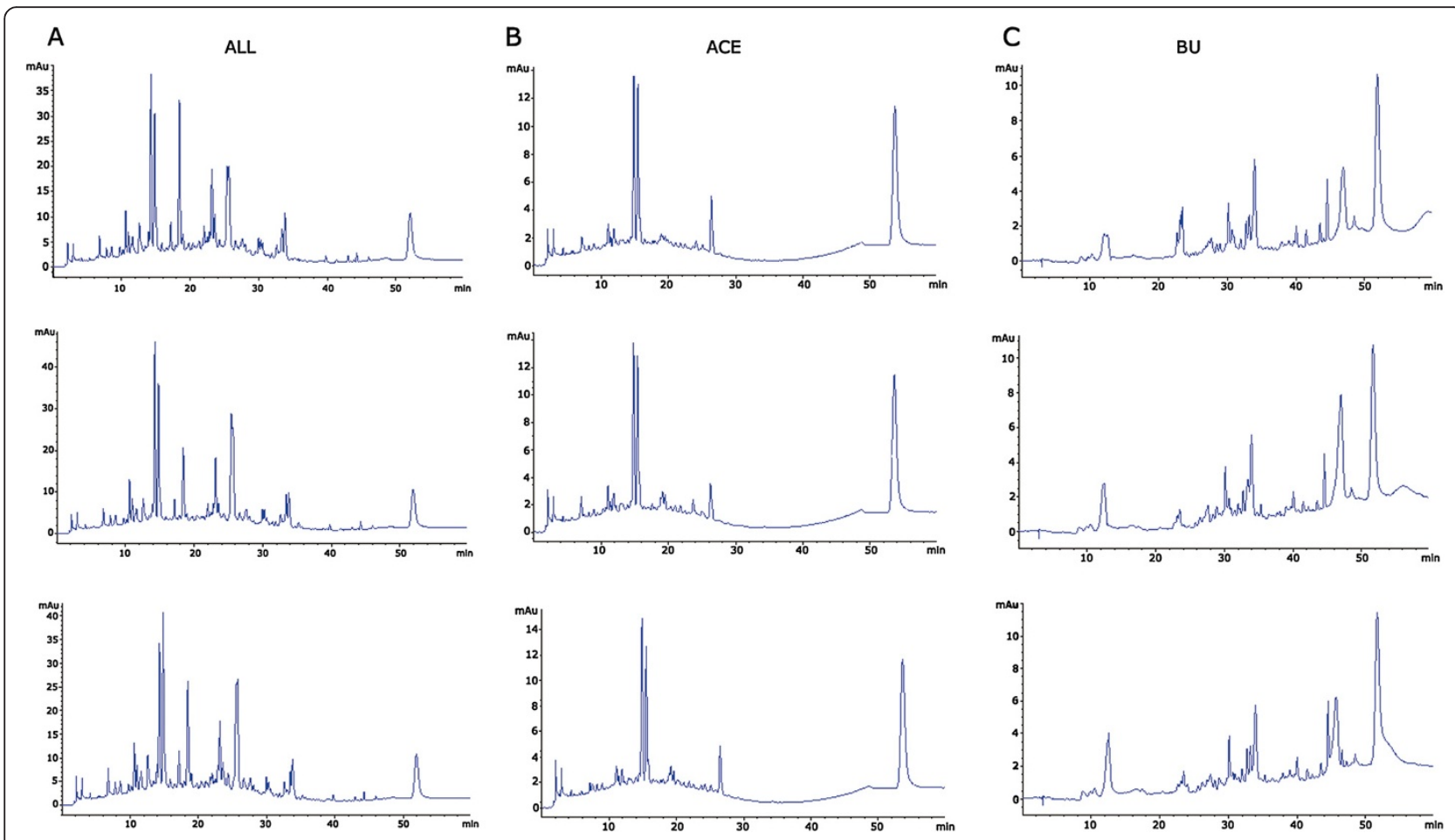

Figure 3 The stability of the extracts and the preparation technology. Total crude extracts (A), ACE extracts (B) and BU extracts (C) was analyzed using a liquid chromatograph. Figures shown were selected from the experiments repeated for four times. 

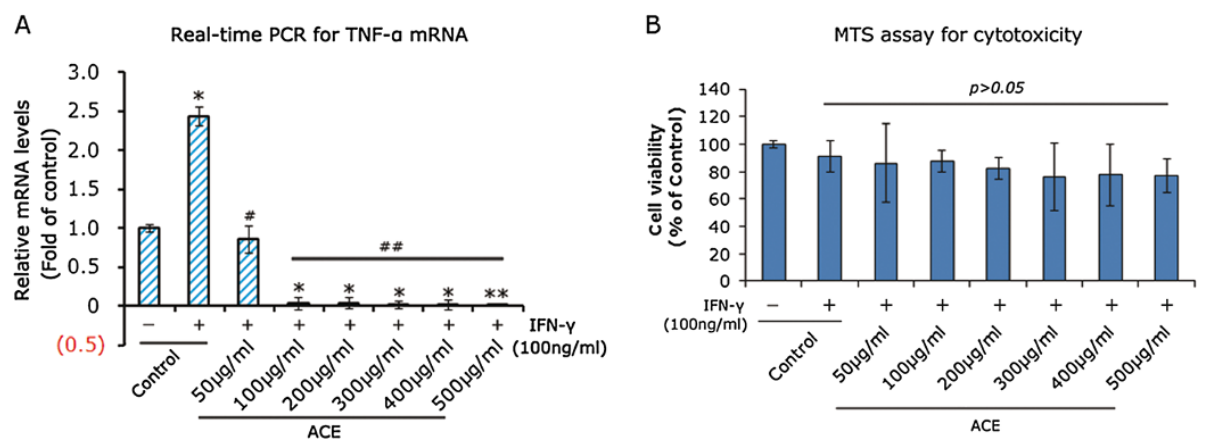

Figure 4 ACE extracts suppressed TNF-a expression with a low cytotoxicity. M1-polarized RAW264.7 was treated graded levels of ACE extracts for $24 \mathrm{~h}$. A. Real-time PCR evaluation of TNF-a mRNA expression in M1-polarized RAW264.7. RAW264.7 without treatment was used as the additional controls. ${ }^{*} p<0.01$ and ${ }^{* *} P<0.01$ versus RAW264.7 cells without treatment, while $\# p<0.05$ and \#\#p $<0.01$ versus M1-polarized macrophages without treatment. B. The cytotoxicity of ACE extracts was determined by MTS assay, and the results were presented as\% of controls. Data are expressed as mean \pm SD of three independent experiments done in triplicate.

activity. Many pro-inflammatory cytokines, including TNF- $\alpha$ and IL-1, are derived from M1-polarized macrophages, and importantly these cytokines are associated with AS [17,18]. Moreover, M1-polarized macrophages have been demonstrated to be expanded in AS patients [5]. Mouse macrophage-like cell line RAW264.7 is, to some extent, an ideal macrophage model for in-vitro studies [19]. Therefore, in this study, RAW264.7 was used as an in-vitro model, and M1 phenotype was polarized by exposure to IFN- $\gamma[19]$.

Biological agents targeting inflammatory cytokines such as TNF- $\alpha$ have widely used in recent years as effective medications for treating AS, while numerous cases of the appearance of malignant tumors in patients receiving these drugs have been reported [20]. In addition, not all AS patients achieve remission or a major clinical response to NSAIDs and TNF- $\alpha$ blockers [21]. Though biological agents targeting IL-1, anakinra for example, has proven to be well tolerated and indicated in the treatment of rheumatoid arthritis, the data in AS are still lacking. Therefore, are there any alternatives?

BQZ decoction is a famous Chinese medicine formula with a long history for application in the treatment of AS. Crude extracts was prepared from BQZ decoction and subsequently fractioned. The effects of different fractioned extracts on the expression of pro-inflammatory cytokines were screened. Strikingly, in M1-polarized RAW264.7, ACE extracts could significantly suppress mRNA level of TNF- $\alpha$, whereas BU extracts dramatically inhibited IL-1 mRNA expression. These findings suggest that BQZ decoction could be a natural antagonist to pro-inflammatory cytokines. To confirm this data, concentration-dependent experiments were conducted subsequently. The discovery of that TNF- $\alpha$ mRNA expression could be totally inhibited by ACE extracts suggests that $\mathrm{BQZ}$ decoction can be an alternative medication in AS patients intolerance to TNF- $\alpha$ blockers [21].

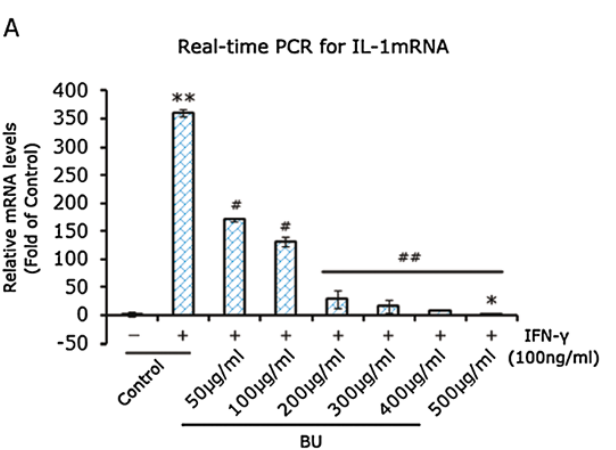

B

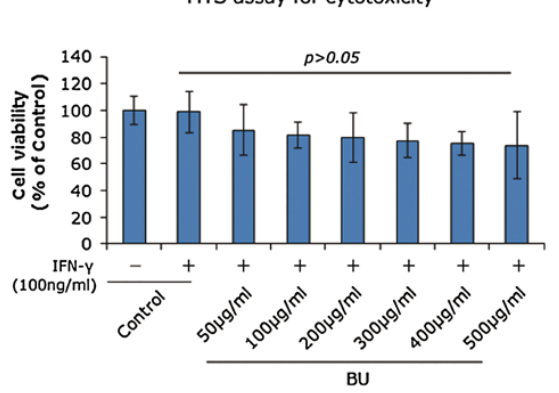

Figure 5 BU extracts suppressed IL-1 expression with a low cytotoxicity. M1-polarized RAW264.7 was treated graded levels of BU extracts for $24 \mathrm{~h}$. A. Real-time PCR evaluation of IL-1 mRNA expression in M1-polarized RAW264.7. RAW264.7 without treatment was used as the additional controls. ${ }^{*} p<0.01$ and ${ }^{*} \mathrm{P}<0.01$ versus RAW264.7 without treatment, while \#p $<0.05$ and \#\#p $<0.01$ versus M1-polarized RAW264.7 without treatment. B. The cytotoxicity of BU extracts was determined by MTS assay, and the results were presented as\% of controls. Data are expressed as mean \pm SD of three independent experiments done in triplicate. 
It is well-known that chronic inflammation in AS can lead to extensive new bone formation throughout the spine [22], and importantly, IL-1 may result in stimulation of bone formation [23,24]. The data that expression of IL-1 mRNA was completely blocked by BU extracts implies that BQZ decoction is capable of relieving new bone formation. Therefore, BQZ decoction might be a better medication than many other biological agents targeting TNF- $\alpha$, such as infliximab, etanercept, adalimumab, as the treatment of these agents does not halt new bone formation [25].

In addition, we tested if the decrease of TNF- $\alpha$ and IL-1 was due to the death of cells. Herein, MTS assays were conducted and the results turned out to be negative. Both ACE and BU extracts could not induce cell death in M1-polarized RAW264.7, suggesting the low cytotoxicity of the extracts of BQZ decoction. Considering modified $\mathrm{BQZ}$ decoction was more efficacious than sulfasalazine [10], the lower cytotoxicity of the extracts of BQZ decoction suggests that, compared with those Western medications, traditional Chinese medications could be a safer and better choice for treating AS.

\section{Conclusion}

In summary, with the low cytotoxicity, crude extracts of BQZ decoction fractioned with ACE and BU could block TNF- $\alpha$ and IL-1 mRNA expression in M1-polarized RAW264.7 respectively, suggesting that BQZ decoction could be an better and alternative medication for treating AS patients. Further analysis of fractioned extracts of BQZ decoction may lead to some novel drugs for treating AS with more efficacious and low toxicity.

\section{Competing interests}

The authors declared that they have no competing interests.

\section{Authors' contributions}

Conceived and designed the experiments: YTH and RYH. Performed the experiments: $\mathrm{RYH}, J \mathrm{HL}, \mathrm{XHH}, \mathrm{XL}, \mathrm{CLL}, \mathrm{YYZ}$ and JC; Analyzed the data: $\mathrm{RYH}$ and $\mathrm{YTH}$; Contributed reagents/materials/analysis tools: $\mathrm{YTH}$; Wrote the manuscript: RYH; Reviewed paper: YTH. All authors read and approved the final manuscript.

\section{Acknowledgments}

This study was supported by National Natural Science Foundation of China (No. 81273736).

\footnotetext{
Author details

'Department of Rheumatology, The Second Affiliated Hospital, Guangzhou University of Chinese Medicine (Guangdong Provincial Hospital of Chinese Medicine), Guangzhou 510006, China. ${ }^{2}$ Central Laboratory, The Second Affiliated Hospital, Guangzhou University of Chinese Medicine (Guangdong Provincial Hospital of Chinese Medicine), Guangzhou 510006, China. ${ }^{3}$ Department of Cerebral Surgery, The Second Affiliated Hospital, Guangzhou University of Chinese Medicine (Guangdong Provincial Hospital of Chinese Medicine), Guangzhou 510006, China.
}

Received: 22 May 2014 Accepted: 17 July 2014

Published: 28 July 2014

\section{References}

1. Genre F, López-Mejías R, Miranda-Filloy JA, Ubilla B, Carnero-López B, Blanco R, Pina T, González-Juanatey C, Llorca J, González-Gay MA: Adipokines, Biomarkers of Endothelial Activation, and Metabolic Syndrome in Patients with Ankylosing Spondylitis. Biomed Res Int 2014, 2014:860651.

2. Zhai J, Rong J, Li Q, Gu J: Immunogenetic study in Chinese population with ankylosing spondylitis: are there specific genes recently disclosed? Clin Dev Immunol 2013, 2013:419357.

3. Slobodin G, Rosner I, Rimar D, Boulman N, Rozenbaum M, Odeh M: Ankylosing spondylitis: field in progress. Isr Med AssoC J 2012, 14:763-767.

4. Senabre-Gallego JM, Santos-Ramírez C, Santos-Soler G, Salas-Heredia E, Sánchez-Barrioluengo M, Barber X, Rosas J, AIRE-MB group: Long-term safety and efficacy of etanercept in the treatment of ankylosing spondylitis. Patient Prefer Adherence 2013, 7:961-972.

5. Ciccia F, Alessandro R, Rizzo A, Accardo-Palumbo A, Raimondo S, Raiata F, Guggino G, Giardina A, De Leo G, Sireci G, Triolo G: Macrophage phenotype in the subclinical gut inflammation of patients with ankylosing spondylitis. Rheumatology (Oxford) 2014, 53:104-113.

6. Baczynska D, Michalowska D, Witkiewicz W: The role of microRNA in ischemic diseases-impact on the regulation of inflammatory, apoptosis and angiogenesis processes. Przegl Lek 2013, 70:135-142. Article in Polish.

7. Maruotti N, Annese T, Cantatore FP, Ribatti D: Macrophages and angiogenesis in rheumatic diseases. Vasc Cell 2013, 5:11.

8. Mizia-Malarz A, Sobol G, Wos H: Angiogenesis in the chronic inflammatory diseases and malignancies. Pol Merkur Lekarski 2008, 24:185-189. Article in Polish.

9. He YT, Ou AH, Yang XB, Chen W, Fu LY, Lu AP, Yan XP, Feng XH, Su L, Song YJ, Zeng SP, Liu W, Qian X, Zhu WH, Lao YR, Xu WH, Wen ZH, He XH, Wang $B J$, Chen GX, Xue SQ: Traditional Chinese medicine versus western medicine as used in China in the management of rheumatoid arthritis: a randomized, single-blind, 24-week study. Rheumatol Int 2014, 24. Epub ahead of print.

10. Szekanecz Z, Koch AE: Mechanisms of disease: angiogenesis in inflammatory diseases. Nat Clin Pract Rheumatol 2007, 3:635-643.

11. Li $X$, Zhang $Y$, Zeng $X$, Yang $L$, Deng $Y$ : Chemical profiling of bioactive constituents in Sarcandra glabra and its preparations using ultrahigh-pressure liquid chromatography coupled with LTQ Orbitrap mass spectrometry. Rapid Commun Mass Spectrom 2011, 25:2439-2447.

12. Davis MJ, Tsang TM, Qiu Y, Dayrit JK, Freij JB, Huffnagle GB, Olszewski MA: Macrophage M1/M2 polarization dynamically adapts to changes in cytokine microenvironments in Cryptococcus neoformans infection. mBio 2013, 4:e00264-00213.

13. Alvarez-Navarro C, de Lopez Castro JA: ERAP1 structure, function and pathogenetic role in ankylosing spondylitis and other MHC-associated diseases. Mol Immunol 2014, 57:12-21.

14. Singh A, Talekar M, Raikar A, Amiji M: Macrophage-targeted delivery systems for nucleic acid therapy of inflammatory diseases. $J$ Control Release 2014, 14:00239-9.

15. Kharraz Y, Guerra J, Mann CJ, Serrano AL, Munoz-Canoves P: Macrophage plasticity and the role of inflammation in skeletal muscle repair. Mediators Inflamm 2013, 2013:491497.

16. Locati M, Mantovani A, Sica A: Macrophage activation and polarization as an adaptive component of innate immunity. Adv Immuno/ 2012, 120:163-184.

17. Monnet D, Kadi A, Izac B, Lebrun N, Letourneur F, Zinovieva E, Said-Nahal R, Chiocchia G, Breban M: Association between the IL-1 family gene cluster and spondyloarthritis. Ann Rheum Dis 2012, 71:885-890.

18. Lea WI, Lee $\mathrm{YH}$ : The associations between interleukin-1 polymorphisms and susceptibility to ankylosing spondylitis: a meta-analysis. Joint Bone Spine 2012, 79:370-374.

19. Hiroi M, Sakaeda Y, Yamaguchi H, Ohmori Y: Anti-inflammatory cytokine interleukin-4 inhibits inducible nitric oxide synthase gene expression in the mouse macrophage cell line RAW264.7 through the repression of octamer-dependent transcription. Mediators Inflamm 2013, 2013:369693.

20. Sifuentes Giraldo W, Gonzalez Garcia A, Tojeiro SC, Sanchez-Sanchez O, Pian H, Diaz MV: Colonic perforation secondary to metastatic lung adenocarcinoma during anti-TNF treatment for ankylosing spondylitis. Acta Reumatol Port 2014, 39:72-76.

21. Kiltz U, Heldmann F, Baraliakos X, Braun J: Treatment of ankylosing spondylitis in patients refractory to TNF-inhibition: are there alternatives? Curr Opin Rheumatol 2012, 24:252-260. 
22. Kim TH, Stone M, Payne U, Zhang X, lonescu M, Lobanok T, King L, Poole AR, Inman RD: Cartilage biomarkers in ankylosing spondylitis: relationship to clinical variables and treatment response. Arthritis Rheum 2005, 52:885-891.

23. Strand V, Kavanaugh AF: The role of interleukin-1 in bone resorption in rheumatoid arthritis. Rheumatology (Oxford) 2004, 43(3):iii10-iii16.

24. Watrous DA, Andrews BS: The metabolism and immunology of bone. Semin Arthritis Rheum 1989, 19:45-65.

25. Hreggvidsdottir HS, Noordenbos T, Baeten DL: Inflammatory pathways in spondyloarthritis. Mol Immunol 2014, 57:28-37.

doi:10.1186/1472-6882-14-268

Cite this article as: Huang et al:: Anti-inflammatory activity of extracts of Bushen-Qiangdu-Zhilv decoction, a Chinese medicinal formula, in M1-polarized RAW264.7. BMC Complementary and Alternative Medicine 2014 14:268.

\section{Submit your next manuscript to BioMed Central and take full advantage of:}

- Convenient online submission

- Thorough peer review

- No space constraints or color figure charges

- Immediate publication on acceptance

- Inclusion in PubMed, CAS, Scopus and Google Scholar

- Research which is freely available for redistribution 